\title{
Patrimonio urbano: el apogeo de los centros históricos y su complejidad reconocida
}

Amparo De Urbina González | Facultad de Ciencias Sociales y Humanidades, Universidad Externado de Colombia

URL de la contribución <www.iaph.es/revistaph/index.php/revistaph/article/view/3888>

Según Jori (2008) la emergencia del urbanismo en la valoración, gestión y conservación del patrimonio urbano han ido adquiriendo un carácter más prioritario desde la década de los 80 del siglo XX, con el reto siempre presente de incorporarlos en la ciudad contemporánea. Refiriéndose a los centros históricos de la América Latina, Fernando Carrión (2012) señala que los debates que se están dando en los últimos años, desarrollándose en torno a la gestión pública de estos centros históricos, responden a un momento coyuntural, donde se están poniendo en cuestión los paradigmas hegemónicos construidos alrededor del manejo del patrimonio.

Esto tiene que ver con tres componentes: el primero se refiere a cambios en las dinámicas demográficas; el segundo a cambios en la lógica de la globalización; y el tercero en las acciones directas e indirectas que se impulsan en sectores patrimoniales (CARRIÓN, 2012: $52,53)$. Con la disminución de migraciones del campo a la ciudad, y el incremento de migraciones internacionales, viene un proceso de reducción de las tasas de urbanización, produciéndose el traslado de la ciudad de la periferia a la ciudad existente, lo que incrementa la importancia de la ciudad consolidada y, dentro de ella, la re-definición y el peso del patrimonio urbano, esto en un contexto donde las ciudades se convierten en nodos de articulación y lugares estratégicos, transformando lo urbano y lo patrimonial. Las centralidades históricas cambian y se pluralizan, se integran internacionalmente privilegiando la ciudad consolidada (CARRIÓN, 2012: 52).

En lo político la democracia pasa de estar sustentada en la igualdad hacia otra que respeta a la diversidad; esto democratiza el patrimonio, transformando los sentidos de apropiación y reconocimiento de pluralidad; de ahí que surjan una multiplicidad de actores patrimoniales -nuevos y antiguos-, conduciendo a formas de gestión disímiles, que se manifiestan en la disputa por su apropiación. El centro histórico, entendido como una construcción de la política pública, que nace cuando el poder político lo delimita en un territorio dentro de la ciudad en representación de la sociedad (CARRIÓN, 2012: 56), se convierte en un escenario estratégico y de disputas, donde el marco normativo del patrimonio debe necesariamente armonizarse con las políticas urbanas y no solo imponerse (CARRIÓN, 2006: 5).

Este nuevo rol de las ciudades, provoca que estas compitan y cooperen entre sí por encima de los estados nación, los cuales entran en crisis por la globalización -apertura económica- y el incremento del peso local descentralización-; la descentralización construye nuevos equilibrios de poder dentro de los estados nación, dándole mayor peso al mercado, lo que impacta las políticas públicas. La introducción de una lógica privada en la gestión de la ciudad promueve un cambio sustancial en el marco institucional municipal, que se expresa en dinámicas de cooperación público-privada, en la producción de servicios e infraestructuras (base material de la ciudad). Este conjunto de elementos, intervienen y modifican la relación existente entre autoridad, sociedad local y estado, dándole autonomía a los municipios frente a la nación, pero más dependencia del mercado (CARRIÓN, 2012: 53).

Los centros históricos se convierten entonces en uno de los lugares más emblemáticos de la ciudad consolidada, no solo por su concentración de bienes de interés cultural e importancia funcional, sino también por la multiplicidad de actores presentes - $y$ afectados- en un momento en el que la ciudad se plantea una nueva integración en el marco de la globalización, lo que la lleva de definir nuevas funcionalidades y a perder otras. Todos estos 


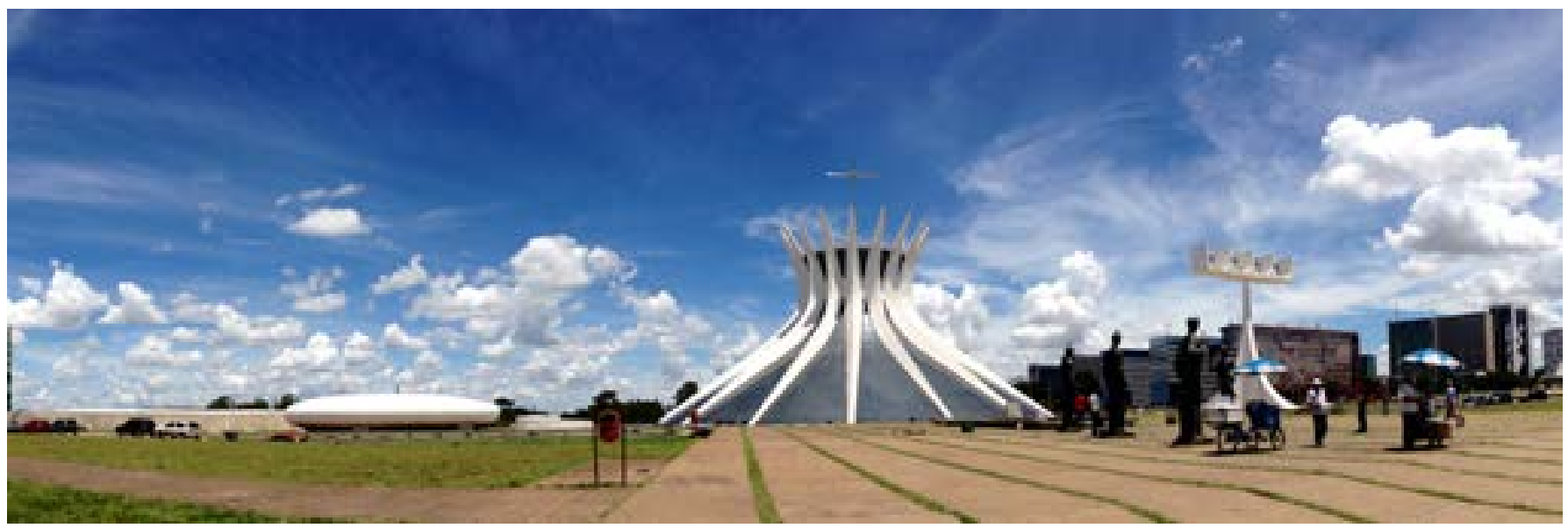

Brasilia | foto Luigi Guarino

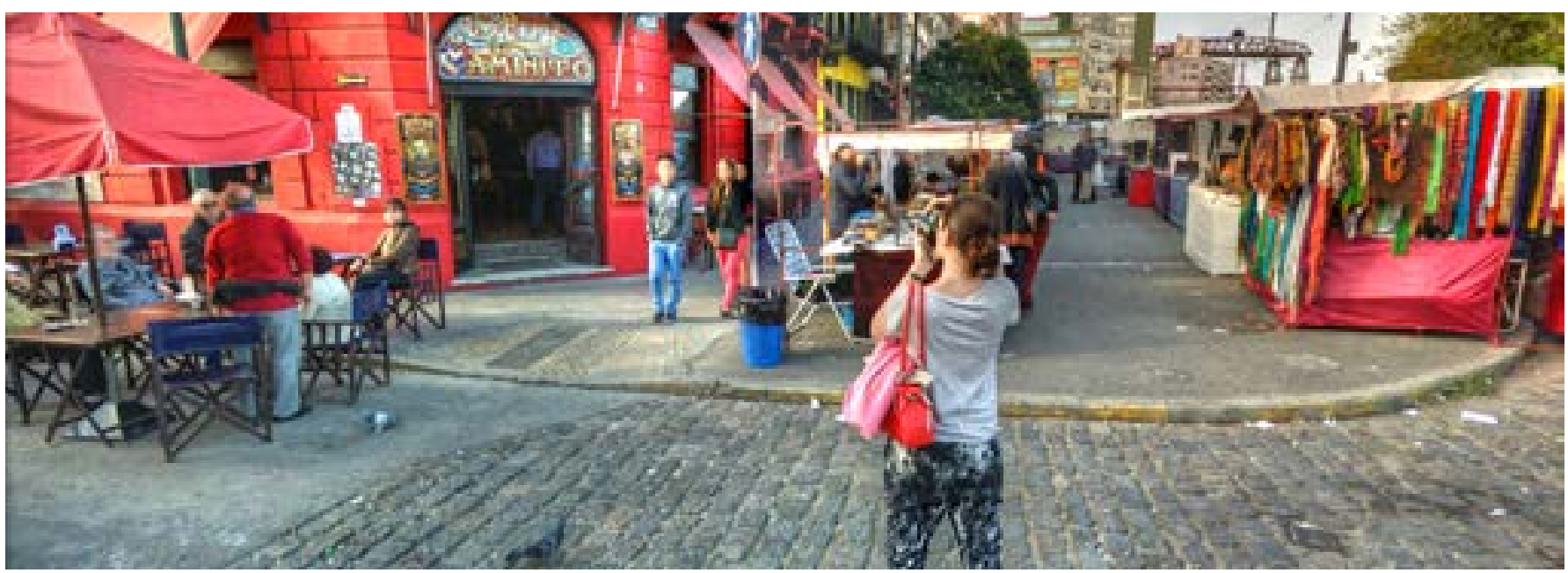

Buenos Aires | foto Kevin Dooley

cambios imponen la necesidad de re-definir las formas de comprensión del patrimonio, así como de la actuación frente a él, lo que impone un cambio de los paradigmas con los que se ha venido actuando (CARRIÓN, 2006: 3).

Frente a una mirada crítica en torno a la valoración de sectores patrimoniales como paso previo a estas intervenciones, y a la necesidad de proponer diagnósticos urbanos para centros históricos que logren incorporar todas las dimensiones propias de los centros históricos, se han encontrado pocas reflexiones. Un autor que ha resultado de gran utilidad para abordar y comprender mejor el tema es Alfonso Álvarez Mora, quien, a partir de una crítica a las prácticas de restauración en sectores patrimoniales, desarrolla una postura frente a los ejercicios de valoración:

"El monumento catalogado, en este sentido, deja de ser un elemento inmerso en la complejidad de la ciudad histórica, tal y como se había heredado, para desempeñar, a partir de las transformaciones a que se somete la ciudad en su conjunto, un papel de articulador formal de la nueva ordenación a que se somete el espacio urbano" (ÁLVAREZ MORA, 2006: 22). 


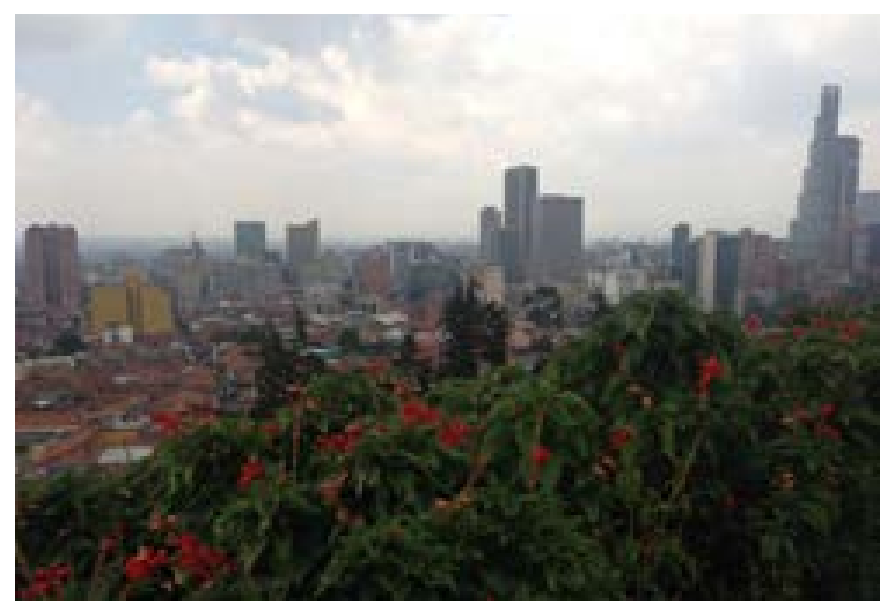

Centro histórico de Bogotá, Colombia | foto Amparo De Urbina González

Para el autor (ÁLVAREZ MORA, 2006: 13) la visión clásica que se construye de los centros históricos se basa en su caracterización desde valoraciones de sus "ambientes monumentales", que responden a su vez a la tradición de entender estos sectores urbanos como un "monumento". Se considera lo monumental como un objeto inanimado, sin relaciones, solo con atributos físicos (CARRIÓN, 2012: 58).

"Y es para ponerlos en valor cómo se procede a separarlos, a hacerles prescindir, a apartarlos, del contenido social responsable de su actual 'disponibilidad económica'. 'Poner en valor' un bien patrimonial, en este sentido, implica extraerlo, desvincularlo de su 'contexto valedor', para exponerlo al servicio de otro. (...) En cualquier caso, dicha 'puesta en valor' supone, como primera medida, despojar, al bien patrimonial sobre el que se actúa, de todo aquello que lo ha valorado históricamente" (ÁLVAREZ MORA, 2006: 183).

\section{BIBLIOGRAFÍA}

- Álvarez morA, A. (2006) El mito del centro histórico. El espacio del prestigio y de la desigualdad. Puebla: Universidad Iberoamericana Puebla, 2006

- CARRIón, F. (2012) Aproximación distante a los paisajes culturales: el caso de los centros históricos. En Paisajes Culturales: Reflexiones conceptuales y metodologías. Memorias del I Encuentro de Expertos. Cuenca: s.n., 2012, pp. 51-60

- CARRIÓN, F. (ed.) (2006) La recuperación de la ciudad. Centros históricos. Mesa de trabajo. En I Encuentro sobre Arquitectura, Vivienda y Ciudad en Andalucía y América Latina. En prensa. Cadiz, 2006, pp. 2-7

- CHOAY, F. (2009) El reino de lo urbano y la muerte de la ciudad. Andamios, vol. 6, n. ${ }^{\circ} 12$, diciembre 2009, pp. 157-187

- ChOAY, F. (2007) Alegoría del patrimonio. María Bertrand Suazo [trad.]. Barcelona: Ed. Gustavo Gili, 2007, p. 264

- JORI, G. (2008) Alegoría del patrimonio. Françoise Choay. Reseña. Revista de Geografía Norte Grande, diciembre de 2008, Santiago de Chile, pp. 147-150

- LULLE, T.; URBINA, A. DE (ed.) (2011) Vivir en el Centro Histórico de Bogotá. Patrimonio construido y actores urbanos. Bogotá: Editorial Universidad Externado de Colombia, 2011

- LUQUe AZCONA, E.; SMITH, H. (ed.) (2007) Novedades y retos en la gestión de centros históricos de Europa, Latinoamérica y El Caribe (1980-2005). Scripta Nova. Revista electrónica de geografía y ciencias sociales, vol. XI, 254, diciembre de 2007

- PARDO, S. (2015) Las vistas panorámicas de núcleos urbanos: propuesta para su análisis y aplicación al caso de Andalucía. Tesis doctoral inédita. Universidad de Málaga, 2015, p. 718

- PARIAS DURÁN, A.; PALACIO TAMAYO, D. C. (2006) Construcción de lugares patrimonio. El centro historico y el humedal Córdoba. Bogotá: Universidad Externado de Colombia; COLCIENCIAS, 2006, p. 477

- RUIZ, D.; CADENAS, C.E. (2005) ¿Qué es una política pública? IUS: Revista Jurídica, n. ${ }^{\circ} 18$ julio-septiembre 2005 <http://www.unla.mx/iusunla18/reflexion/QUE\%20 ES\%20UNA\%20POLITICA\%20PUBLICA\%20web. htm\#_edn1> [Consulta: 13/03/2017]

- SANTANA, P. (2008) La participación ciudadana en el nuevo Plan de Desarrollo Distrital. Viva la Ciudadanía, $2008<$ <ttp://viva.org.co/cajavirtual/svc0096/articulo04. pdf> [Consulta:1/2/2017]

- VARGAS, J. C. (2011) El laberinto de los convocados. Planeación urbana y participación ciudadana en torno al plan zonal centro de Bogotá. Tesis de pre grado inédita. Universidad Externado de Colombia. Bogotá, 2011 